\title{
GEOGRAFIA, EDUCAÇÃO, LINGUAGEM: ELEMENTOS DE UMA RECONSTRUÇÃO ONTOLÓGICA?
}

\author{
Nelson Rego \\ Professor da Pós-Graduação em Geografia da Universidade Federal do Rio Grande do Sul. \\ nelson.rego@ufrgs.br
}

\begin{abstract}
Resumo
O Exame, no contexto brasileiro do encontro entre geografia e educação, de relatos de práticas e de construções teóricas relativas a estas práticas, referenciando a indagação acerca da pertinência em propor que, nesse encontro, podem ser observados indícios de uma reconstrução ontológica.
\end{abstract}

Palavras-chave: Geografia. Educação. Linguagem. Práxis. Reconstrução ontológica.

\begin{abstract}
An examination, in a Brazilian context of a convergence between geography and education, of reports of practices and theoretical constructs concerning these practices, making reference to the inquiry surrounding the relevance in proposing that indications of an ontological reconstruction may be noted through this convergence.
\end{abstract}

Key Words: Geography. Education. Language. Praxis. Ontological reconstruction.

\section{$\circ \bigcirc \circ$}

\section{INTRODUÇÃO}

O exame de práticas e de construções teóricas relacionadas a estas práticas, de muitos daqueles que, no Brasil, atuam no ensino escolar da geografia e em experiência de educação não formal, permite indagar se estará em curso, mesmo que em fragmentos, um movimento mediado pela noção de espaço como condição e produto de uma autopoiése humana. Os indícios desse movimento, ou de sua possibilidade, ultrapassam o âmbito do encontro entre a geografia e a educação, porém, neste, encontram veículo privilegiado para atuações e experimentações esclarecedoras acerca do possam ser seus propósitos e métodos.

Esse encontro entre a geografia e a educação - quer se trate da educação formal, ou da educação não formal - constituem exercícios que compreendem de outro modo o espaço e, em pequenas medidas, tornam-se reconstrutores de espaços. Por essa mesma via, tais exercícios tornam-se também contributivos para a reconstrução do ser professor e do ser aluno.

Esse encontro ressalta que o princípio de qualquer prática é inseparável da interrogação axiológica sobre o sentido daquilo que se faz.

Os autores/pesquisadores/atuadores, neste texto referidos, são apenas um recorte entre outros recortes que seriam representativos de um conjunto mais vasto do que comumente talvez seja suposto.

\section{METÁFORA-GUIA}

Fazer a coisa certa não é o mesmo que fazer uma certa coisa. Nesse caso, a ordem dos fatores altera o produto. $\mathrm{O}$ efeito causado com a inversão dos fatores é redobrado pela utilização, num momento, do artigo definido "a" e, no momento subsequente, pelo artigo indefinido "uma". Dá-se o nome de sintaxe a essa relação, multiplicadora de significados, entre as unidades lingüísticas e o texto.

Pode-se esticar, como metáfora, a noção de sintaxe linguística para as relações entre fatos e condições que contextualizam a existência - o que é da linguagem é da vida.

Na vida, como na frase, uma coisa é fazer a coisa certa, e outra é fazer uma certa coisa, que, por vezes, é significada como equivalente a fazer a coisa certa.

Revista da ANPEGE. v. 5, 2009 


\section{O MESMO É OUTRO, SE LIGADO POR DIVERSO MODO AO QUE ESTÁ EM VOLTA}

Ler em sala de aula matéria jornalística sobre pessoas e casas soterradas por desabamento de terra em encosta de morro, ouvir opinião de dois ou três alunos e encerrar o assunto aí - é uma coisa.

Ler a mesma matéria, ouvir a opinião dos estudantes, reconhecer o contraditório ou complementar que se estabelece entre as falas, incentivar o debate, ir a campo para identificar áreas de habitação sujeitas à semelhante risco, entrevistar os moradores para conhecer as razões que os conduzem a viver sob esse risco, comparar dados, pesquisar, compreender o processo histórico que produz essa geografia, discutir alternativas para uma política habitacional, discernir os limites de tais alternativas diante da macroestrutura social, criar mapas hipotéticos de uma outra cidade que seria (im)possível — isso tudo é outra coisa.

Pode-se comparar as duas situações a duas frases iniciadas pela mesma palavra - a matéria jornalística -, onde esse signo inicial representa funções diferentes porque contextualizado por sintaxes interpretáveis como até mesmo opostas.

Na primeira situação, podemos discernir um pastel de vento, termo coloquial apropriado por Kaercher (2004) para designar, em educação, práticas que mantém apenas a aparência de propostas consideradas críticas e inovadoras. Assim como o termo coloquial, que sugere uma embalagem esvaziada de seu conteúdo, Kaercher classifica como pastéis de vento em educação, particularmente no ensino de geografia, práticas que solicitam a multiplicidade das falas, mas não incentivam o exercício de opor, comparar e conciliar argumentos; estimulam a elaboração inicial de perguntas, mas não prosseguem na investigação da dúvida, na busca de respostas e na reelaboração das perguntas.

Pastéis de vento levam a extremos caricaturais algumas máximas, transformando-as em clichês esvaziados do sentido crítico e criativo que buscam aparentar. Por exemplo, torna-se justificativa para o descompromisso em relação à busca de quaisquer respostas a conhecida frase que diz que mais importante do que as respostas são as perguntas, como se perguntas pudessem ser reelaboradas de modo mais perspicaz sem o suporte do processo de equilíbrio/desequilíbrio face a respostas reciprocamente em movimento.

Sintoma revelador do pastel de vento que procura passar-se por educação crítica são as falas que se multiplicam sem jamais tornarem-se diálogos, onde o direito de cada um dizer o que pensa é desacompanhado do exercício de escutar o outro, o que reduz a liberdade de expressão a um falar para as paredes. A receita da caricatura é trazer para a sala de aula referências a temas polêmicos que estejam sob a atenção da mídia - solicita-se aos alunos que cada um manifeste sua opinião e, no primeiro sinal de controvérsia, aborta-se a discussão com a máxima que diz "fulano tem o direito de pensar tal coisa, e beltrano tem o direito de pensar o contrário". São estabelecidos alguns signos participativos, que, contudo, não são articulados numa sintaxe democrática, porque falta, no conjunto, a noção de que a democracia é mais do que a justaposição das diferenças, pois, por fundamento, ela é interação entre as diferenças. Ela as transforma, estabelecendo transitórias maiorias e minorias, no mesmo movimento em que perguntas e respostas devolvem-se uma às outras e o contraditório dos argumentos alterna-se com a conciliação de acordos.

Esse pastel de vento escolar, ao inverso do que afirmam os clichês que o sustentam, talvez não eduque para a cidadania, mas para a submissão do debate interacionista ao império da opinião que fala e deixa falar, mas não quer escutar, nem é escutada, e que não aprende a estabelecer acordos para a ação.

Nesse sentido, embora existam signos semelhantes em ambas as situações, suas sintaxes podem ser interpretadas como divergentes. A primeira seria o simulacro da segunda. $\mathrm{O}$ simulacro, aqui, não tem o significado de uma versão simplificadora de outro tomado como referencial. Uma versão simplificada ainda pode destacar algo de definidor ou nuclear do imitado. O simulacro, diferentemente, executa uma 
cópia parcial da aparência no mesmo ato em que dilui o processo que, no referencial, estabelece outros caminhos a partir da porta de entrada oferecida pela aparência.

Porém, o que busca Kaercher que, ao observar práticas pedagógicas em salas de aula, apropria-se do termo pastel de vento para dar nome e compreensão ao que ali acontece? Como a própria pergunta evidencia, uma resposta nela já está indicada: para dar nome e compreensão ao que acontece, para criar chaves de leitura. Mas quem busca chaves de leituras, para compreender o de sempre por outro modo, assim o faz movido por quais desejos de novas construções?

Supõe-se, nessa busca, uma dialética do esclarecimento. Algum projeto antagoniza-se com uma situação dada, elabora leituras críticas que o manifestam como alternativa ao criticado e, ao manifestar-se, torna-se exposto, ele mesmo, a questionamentos; torna-se solicitado a esclarecer-se, a ampliar-se pela ponderação com o contraditório, a desenvolver-se como projeto e a incluir-se em projetos construídos em rede no campo aberto da dialógica.

\section{LIGAÇÕES AMPLIAM SIGNIFICADOS QUE AMPLIAM LIGAÇÕES}

Se o encontro da geografia com a educação gera um campo na fronteira sem limites fixos entre esses dois campos maiores - e se protagonistas teorizam sobre as práticas e, nesse diálogo, configuram o próprio campo -, o discurso de cada protagonista pode ser uma porta de entrada para uma visão sobre o discurso dos outros, uma porta de entrada para o campo.

Quem busca chaves de leitura para compreender o de sempre por outro modo, assim o faz movido por quais desejos de novas construções?

Schäffer e Kaercher (2008), por exemplo, referem-se a Goulart (2007) para evidenciarem que será pela palavra do outro - de muitos outros - que cada aluno virá a refazer a palavra que lhe era prévia a esse encontro. Sendo que as palavras desses muitos outros remetem ao mundo composto por interações entre escalas, pois, agenciadas pela mediação do professor, tais palavras não se limitam àquelas pronunciadas pelos alunos situados numa mesma horizontalidade. São palavras atravessadas desde outros lugares: vindas do jornal, do rádio e da TV, dos sites de informação e de relacionamentos. São também as palavras encontradas na música, no filme e na charge. São palavras colhidas na leitura mais atenta do livro didático, agora contrastado pela leitura de outras fontes. No exercício de aprimorar a leitura e a escuta, as palavras serão também as pronunciadas pelos habitantes do lugar e as captadas na paisagem, no mapa, na foto orbital enviada pelo satélite. Schäffer e Kaercher, interpretando o relato reflexivo de Goulart, identificam possibilidades abertas pelo professor recriado como um mediador que incentiva, entre os participantes, o desenvolvimento das elaborações pessoais acerca desses significados escutados e lidos nos atravessamentos de palavras e escalas.

A prática pedagógica relatada por Goulart é referente ao desafio de ajudar a reverter entre alunos trabalhadores a expectativa de que jamais aprenderão os conteúdos escolares. Tal expectativa, entre adultos que retornam à educação formal, está calcada na imagem construída de que, se não aprenderam quando jovens, não será em idade mais avançada, com o tempo consumido pelo trabalho diário, que conseguirão. O desafio consiste em despertar o interesse pelo conhecimento, pela pesquisa e pelo debate; interesse que está implícito no próprio ato de retornar à escola, mas que, na ambivalência humana, é negado pelo introjetado sentimento do fracasso. Ao fundo, o desafio consiste em ajudar a reconstruir a imagem do pretérito fracasso escolar, agora a ser significado não mais como uma derrota pessoal, mas como um produto social e institucional. 
Goulart elege, como caminho, fazer constantes atravessamentos entre os temas do contexto mais proximamente vivido e os temas de outros lugares, buscando compará-los, contrastá-los e estabelecer conexões. Nessa prática, evidencia-se que será impossível ao professor ser a fonte de todas as informações e de todos os argumentos. Deverá ser, então, aquele que indica possibilidades para a realização das buscas e faz mediações entre as descobertas e as falas.

Goulart estabelece como chave de leitura, ou de caminho, para fazer de outro modo a educação, a desconstrução de papéis aos quais os sujeitos traziam internalizados, como alunos e como trabalhadores: não mais apenas ouvir, mas questionar; não mais apenas responder, mas perguntar; não mais apenas entender (reproduzir a informação), mas buscar mais.

Schäffer e Kaercher, lendo e escutando as leituras e escutas de outros, entre estes, Goulart, elaboram como chave de caminho que algo que está posto em questão, na reinvenção da docência, é a elevação da capacidade criativa de... ler e escutar.

É sobre o desenvolvimento da capacidade de ler imagens que se interrogam e nos interrogam Frange e Vasconcellos (2004), ao estabelecerem diálogos com as obras criadas por adolescentes e crianças em oficinas de desenhos urbanos. Cerca de 2.600 desenhos, feitos em praças de Uberlândia e de seus quatro distritos, realizados em sucessivas oficinas, de 2001 a 2004, expõem a visão de jovens sobre a cidade de suas vivências. Em sua maioria, convidados junto a escolas públicas, os jovens desenham a cidade tal como eles a enxergam e como desejariam que ela se tornasse.

Acompanhados por uma equipe multidisciplinar, Frange e Vasconcellos interrogam sobre o melhor modo para conversar com os desenhos. A resposta fundamental é: interrogar. Cada intérprete não precisa omitir-se como sujeito, ao contrário, indaga a partir de seu lugar - geógrafo, urbanista, pedagogo, artista plástico e assim por diante. Diante do universo misterioso e inconcluso do desenho, cada perguntador oferece suas interrogações. O universo dos desenhos é multiplicado pelo universo das perguntas, gerando um encontro onde proliferam as pulsões da vida tanto individual quanto coletiva diante do urbano.

Diversa maneira de conversar com as imagens é exercer agrupamentos vários, seja escolhendo alguns desenhos para comporem tiras de postais, sob critérios que o olhar de outros haverá de tentar elucidar, seja selecionando desenhos para serem comentados, e novamente indagados, em publicações que registrem as oficinas.

Talvez o mais contundente modo de realizar agrupamentos tenha sido o de compor grandes cartazes de rua com a união de muitos desenhos, tornando possível que mesmo o fugaz passante no interior de um automóvel captasse algo dos desejos e estranhamentos, esperanças e indignações pulsantes nos cartazes.

Em todos esses casos, Frange, Vasconcellos e equipe interrogaram-se pelas sintaxes possíveis, propuseram sintaxes: ligando inicialmente elementos para comporem uma proposta de intervenção (cidade, escola, desenho feito na praça, convite, criança, adolescente, o que eu vejo existir, o que eu gostaria que existisse); ligando perguntas às imagens; ligando desenhos com desenhos sob critérios vários; ligando grupos de desenhos a meios para torná-los visíveis ao olhar de outros.

Na leitura interrogante dos desenhos, Frange, Vasconcellos e equipe sugerem, nas imagens, a emergência de um outro urbano que se contrasta com a cidade funcional, voltada para a produtividade e que vai se tornando grande em ritmo acelerado, e sobre a qual se costuma conhecer apenas uma parte de sua história, de suas vitórias e derrotas. Frange, Vasconcellos e equipe encontram nos desenhos uma profusão de relações humanas colocadas para além do produtivismo, representadas em espaços à margem (e, às vezes, no centro) de espaços urbanos enclausurados em paisagens de concreto e fumaça. Discernem espaços alternativos onde a natureza, transformada em jardim, aparece como cenário para esse humano que consegue deixar em suspenso o ritmo aligeirado representado por outras partes da imagem.

Revista da ANPEGE v. 5, 2009 
Consideram que crianças e adolescentes exteriorizam suas cidades internas, numa relação em que o "lá, fora de mim" e o "aqui, dentro de mim" não constituem os dois lados meramente fixos numa oposição estanque, mas, sim, posições em movimento. A cidade interna, ao se exteriorizar, torna-se uma sugestão para o futuro da cidade externa, ainda mais - muito mais - se as oficinas pautam-se por buscar ligações comunicacionais entre os desenhos sobre o urbano e os sujeitos do urbano.

A sintaxe é estendida até o poder público, pois os oficineiros significam os desenhos como proposições e, como tal, práticas cidadãs que remetem, sob forma imagética, demandas aos órgãos dos poderes públicos e a instituições da sociedade civil, onde a leitura poderá encontrar interstícios de felicidade na trama densa de cenários conturbados.

Essa duplicidade na direção do diálogo (com a imagem e a partir da imagem) pode ser também observada nas práticas de Galvão (2007), que se fundamenta em Kozel (2007) e Rego (2006), ao desenvolver suas perguntas e respostas na relação com mapas mentais feitos por crianças de escolas públicas na periferia urbana de Curitiba.

Kozel define o mapa mental como uma forma de linguagem que dá corpo visível ao modo como o espaço é vivido, manifestando uma multiplicidade de nuances e sendo feito com signos que são, ao mesmo tempo, construções sociais e apropriações singulares destas pelo autor do mapa. Destaca que os mapas mentais, como construções sígnicas, permitem interpretações, lembrando que tais construções estão imersas em ambientes sociais, espaciais e históricos que referenciam as elaborações singulares. Para Kozel, essa interpretação deve ser exercitada através de um dialogismo que não dissocie a construção sígnica da compreensão do homem como ser social; evitando, por um lado, reduzir o exercício interpretativo a um mero enquadramento dos signos a um esquema prévio e externo de atribuição de significados, assim como, na via contrária e recíproca, não olvidando que a expressão individual está referenciada em códigos socialmente construídos e, como tal, pode ser interrogada, dialogizada. Com essa intenção, podem ser propostos sistemas para uma aproximação compreensiva em relação ao mapa mental, a partir das perspectivas de quem procura estabelecer diálogos com os mapas.

Na proposta de Kozel, a partir da perspectiva da afeição da geografia pelo conhecimento do espaço e dos significados destes para os que nele vivem, pode-se estabelecer uma sequência de quesitos, à maneira de uma metodologia, para a observação e interrogação relativas aos mapas mentais:

1 - interpretação quanto à forma de representação dos elementos na imagem;

2 - interpretação quanto à distribuição dos elementos na imagem;

3 - interpretação quanto à especificidade dos ícones:

- Representação dos elementos da paisagem natural,

- Representação dos elementos da paisagem construída,

- Representação dos elementos móveis,

- Representação dos elementos humanos;

\section{APRESENTAÇÃO DE OUTROS ASPECTOS OU PARTICULARIDADES.}

A sequência é proposta como um meio de dialogar com os signos oferecidos pelos mapas mentais e, assim, dialogar a partir dos mapas com os seus autores a respeito daquilo que os mapas propiciam para a compreensão de seus espaços de existência. 
A metodologia proposta por Kozel é utilizada entre outros pesquisadores, por Galvão, que a ela associa a noção de geração de ambiências, desenvolvida por Rego. Galvão, em suas práticas no ensino fundamental, solicita mapas mentais referentes à cidade, para crianças e adolescentes de escolas públicas de Curitiba. Vale-se da sequência proposta por Kozel para observar e interrogar os mapas e, após, para dialogar com os estudantes a partir das leituras provisórias acerca de suas criações. Assim, têm-se como suporte para o diálogo, entre os participantes, tanto o sistema de leitura quanto o grande objeto tomado como referência comum: a cidade de Curitiba.

O trabalho de Galvão, em Curitiba, faz emergir aspectos semelhantes àqueles manifestados nas oficinas conduzidas por Frange e Vasconcellos, em Uberlândia. A cidade aparecida nos mapas subjetivos solicitados por Galvão também comunica um universo polissêmico de desejos e estranhamentos, de esperança e indignações; imagens dentro de imagens que incentivam o observador a interrogar se os contrastes entre interstícios de felicidade e cenários conturbados não constituem, tal como na concepção de Frange e Vasconcellos, discursos que podem se reivindicar como propostas cidadãs dirigidas à dimensão pública.

Galvão desencadeia suas práticas com a intenção de gerar ambiências em conjunto com os estudantes, pois concebe, a partir de uma leitura ampliadora da idéia proposta por Rego, que representar algo já é um modo de agir sobre esse algo, na razão em que se modificam os sentimentos em relação a esse algo no exercício de representá-lo. Mudar os sentimentos corresponde, em parte, a mudar a própria relação. E mudar a relação com algo já é mudar, por pouco que seja, o próprio algo. Por exemplo, mudar o sentimento de rejeição apática, diante de um contexto, para um sentimento de participação crítica corresponde não apenas a uma grande mudança para o sujeito que operou em si a alteração, mas pode ser também, em alguma medida, por pequena que seja, uma mudança para o contexto.

Rego considera que tomar as questões do entorno como suporte para o exercício dialógico, entre sujeitos que estão em busca de chegar a acordos para intervir sobre essas mesmas questões, corresponde a uma práxis educadora que faz compreender que os objetos a serem discutidos (conhecidos) são veículos para o próprio conhecimento relativo à capacidade de ação dos sujeitos. Desse modo, acentua uma reciprocidade entre os esforços para melhorar as condições da geografia proximamente vivida e os esforços que os sujeitos realizam em relação a si mesmos, no sentido de aprenderem, pela prática, os modos pelos quais a participação social se desenvolve.

Com as suas práticas, e ao dialogar com a idéia de Rego, Galvão demonstra o quanto a ação não deve ser considerada apenas como ação imediatamente voltada para a exterioridade pública e para a intervenção sobre o arranjo dos objetos no espaço, mas, igualmente, deve ser considerada ação na delicadeza introspectiva do exercício da representação, por tudo o que este agencia para as mudanças nos vínculos entre sujeito e contexto.

São também esses vínculos — mais precisamente, as práticas que transformam esses vínculos — que ocupam lugar central no relato reflexivo de Pires, Lindau e Rodrigues (2003), ao realizarem pesquisa-ação em vila habitada por catadores de papel, plásticos e outros materiais, na cidade de Porto Alegre. No local, as aulas e investigações de campo formaram conhecimento sobre o significado monetário desses resíduos para as indústrias, que os utilizam como matéria-prima, e para os intermediários, que atuam na compra e venda desses materiais. Tal conhecimento mudou a compreensão dos coletores e demais habitantes da vila sobre o valor econômico daquilo que antes chamavam de lixo. Compreenderam, do mesmo modo, a desproporcional repartição da renda efetuada entre os participantes do mesmo processo, sendo configurada essa desigualdade pela comparação entre sua miséria e os lucros obtidos por industriais e intermediários.

Outro eixo estruturante das atividades foi a busca de conhecimento sobre os efeitos causados pela entrada de diversos tipos de dejetos nos sistemas de troca de matéria e energia existentes no ambiente, 
em diversas escalas. O conhecimento propiciou o questionamento sobre os motivos de os catadores serem considerados marginais, embora sua atividade compense parte dos serviços que o poder público deixa de prestar quanto ao recolhimento de resíduos, assim como supre parte da omissão de indústrias e comércio quanto ao destino desses resíduos resultantes dos processos de produção e consumo que lhes geram os lucros.

Ainda, o trabalho conjunto entre universidade e habitantes da vila urbana, conforme exposto por Pires, Lindau e Rodrigues, apoiou-se sobre outro eixo de pesquisa e experimentação, constituído pelos sentimentos, em mudança, dos moradores em relação aos caracteres formadores da cotidianidade da vila. Buscando praticar uma pesquisa que não se limitasse a resultar apenas em diagnósticos de situações já acontecidas, mas em examinar os significados de ações em curso, e colocadas em movimento também pela própria atividade dos pesquisadores, propuseram oficinas para a criação de artesanatos com a utilização dos resíduos e, a partir das oficinas, a realização de teatros. Esses teatros ora enfatizaram o tema dos resíduos, ora extravasaram o tema inicial e representaram - reinventaram - as pulsões advindas do cotidiano da comunidade. Às aulas e às oficinas de arte e ao teatro, foi associada a prática de esportes e, a esse conjunto de atividades, foi associada a parceria com a escola púbica localizada nas proximidades da vila, ajudando a romper a barreira existente entre vila e escola, como se crianças e adolescentes de uma e de outra não se assemelhassem quanto à condição social, lugar geográfico na borda da cidade e expectativas achatadas quanto ao seu lugar no mundo.

É provável que a mudança da imagem dos habitantes da vila a respeito de si mesmos e de sua atividade como coletores possa ter contribuído para algumas mudanças objetivas acontecidas no lugar, como a mobilização para obter junto ao poder municipal a substituição dos casebres por sobrados de alvenaria e a construção de um galpão para armazenagem e reciclagem de resíduos; ou como a organização de uma cooperativa para eliminar o degrau mais baixo da cadeia de intermediários e, assim, aumentar a renda circulante na vila, ou como o aumento da escolarização entre os habitantes da vila.

É possível observar, na experiência de Pires, Lindau e Rodrigues, a centralidade da atenção dada às ligações estabelecidas e multiplicadas no interior do processo educacional e, a partir deste, com o contexto social; ligações já destacadas nos comentários sobre Kaercher, Schäffer, Goulart, Frange, Vasconcellos, Kozel, Galvão e Rego.

Conforme a metáfora da sintaxe, uma coisa é, em aula de geografia ou de educação ambiental, dar dicas sobre o que fazer com o lixo e outra coisa é dar dicas sobre o que fazer com o lixo e questionar os motivos para a produção de tanto lixo, e interrogar se os danos e ganhos acoplados a essa produção massiva estão socialmente distribuídos com equilíbrio, e hipotetizar soluções e sondar os limites de tais alternativas no contexto global do econômico, do cultural e do político.

Ainda, outra coisa, é conhecer o ambiental não como uma mensagem transmitida por pacotes didáticos, mas com experimentações de possibilidades vividas junto ao territorial, quando o lixo não é apenas o que pode ser visto na rua, no lado de fora da janela, mas, sim, o monturo dentro do qual se vive - ou se vivia.

Esse zelo relativo ao desenvolvimento de ligações de toda ordem acentua a reflexão sobre os significados da práxis, da formação de professores e das linguagens utilizadas.

\section{ESCOLHAS E NARRATIVAS}

Cavalcanti (2005) significa a sala de aula como um lugar configurado pelo desafio de equacionar a necessidade de incentivar as diferenças e, ao mesmo tempo, questionar a desigualdade. O professor é um ser confrontado pela necessidade de ultrapassar sua formação inicial, se quiser responder de maneira positiva a esse desafio, tornando-se continuamente aprendiz das diferenças culturais que se colocam

Revista da ANPEGE. v. 5, 2009 
em cena na sala de aula, para, com essas diferenças, construir o (re)conhecimento do social como algo heterogêneo e permeável à ação modificadora dos indivíduos. O exercício afirmativo das diferenças, para Cavalcanti, acentua a percepção de seu contrário: as representações homogêneas da sociedade, as representações que omitem diferenças marcadas pelo quadro da desigualdade social.

Guerrero (2005) destaca, no diálogo das diferenças, a posição central ocupada pela singularidade do professor. Observa que a socialização do conhecimento geográfico depende de variáveis que transcendem a questão dos conteúdos, observando que, embora existam documentos oficiais com a finalidade de fornecerem parâmetros a respeito daquilo que seria mais relevante para ser ensinado, na prática quem seleciona e formula o currículo do aluno é o professor. Assim, ressaltam-se os fatores motivacionais que possam estar associados às escolhas e conduções protagonizadas pelos professores. Entre esses fatores, situam-se as condições oferecidas pelo contexto escolar e social, como o incentivo, ou não, ao aprimoramento de domínios procedimentais e de diferentes linguagens.

Destaca-se em Cavalcanti e Guerrero, quanto à formação do professor, a associação entre a necessidade de desenvolver as linguagens e a necessidade de compreender, através do vivido, as relações em construção entre o lugar e o mundo.

O exercício de criar expressões escritas, orais e imagéticas sobre o lugar da existência cotidiana é significado por Aigner (2006) como uma das maneiras de dar veículo à proposta de Santos (1994), referente a considerar que o mundo é um conjunto de possibilidades que só podem se realizar através dos lugares e que, nas respostas dadas pelos lugares a essas possibilidades, pode crescer a participação de sujeitos dotados da consciência práxica de que a união viabilizada pela cooperação das diferenças constitui respostas que se contrapõem à expansão de uma cultura competitiva, que, não desmentida pelas manifestações de outras vivências, faz prevalecer a visão única de que só a fragmentação é possível.

Aigner, à semelhança de Guerrero, destaca o papel decisivo de um determinado sujeito — o professor -, que, para além do que pode ser fixado em documentos curriculares, pode ou não escolher incentivar os alunos a exercícios criativos que, falando de seu lugar no mundo, compreendem de outro modo o mundo por modificarem a relação com o lugar.

O trabalho de Aigner, em escolas públicas na periferia de Porto Alegre, revela paralelismos com o trabalho de Freitas (2010), desenvolvido na periferia de Fortaleza. Ao aceitar o desafio de incentivar e mediar narrativas que compreendem de outro modo o mundo, Aigner enfatiza os temas geradores relacionados à condição de ser periferia, com toda a carga de discriminação em que isso implica numa cidade "branca". Freitas refere-se a desafio similar, no contexto de comunidades praianas que sofrem os efeitos do avanço da especulação imobiliária, sendo empurradas em direção à marginalidade e à inversão produzida pelo estigma que diz serem essas pessoas, as empurradas "para fora", a fonte cotidiana de violências.

Ambos, Aigner e Freitas, manifestam a singular identidade de seus contextos, na práxis de incentivar e mediar narrativas. E, ambos, revelam uma universalidade que os aproxima e exemplifica caminhos possíveis para aquilo que Straforini (2004) define como o desafio de relacionar a referência do lugar à compreensão da totalidade-mundo, ou para aquilo que Rego, Suertegaray e Heidrich (2001) significam como a necessidade de compreender o já acontecido a partir de elaborações individuais/coletivas sobre o que deva vir a acontecer.

Esses exemplos práxicos guardam uma proximidade com o que Oliveira Júnior (2002) chama de pontualização, aquilo que é ao mesmo tempo uma singularidade e uma universalização, pois acolhe uma identificação de todos com a manifestação do único. Oliveira Júnior refere-se a um processo que tem concretização em quem está recebendo uma imagem, considerando que ela é entendida simultaneamente 
como um ser singular (um gato preto, uma mesa) e como um signo geral que perpassa os indivíduos (todos os gatos, todas as mesas).

Oliveira Júnior aborda, de modo privilegiado, o audiovisual que veicula a tradição de generalizar algumas poucas imagens/informações e disseminá-las para todos como a verdade acerca de um lugar — processo que funciona em qualquer direção para a qual desejarmos remetê-lo, e com o qual podemos estabelecer relações que flutuam da passividade à crítica e à criação.

Ressalta que, enquanto, de modo mais comum, as narrativas escolares seguem o modelo generalizante do discurso científico, as narrativas audiovisuais seguem uma proposta típica da literatura, que é a de uma visão mais pontual e aproximada em relação ao vivido. Oliveira Júnior recorda-nos que, se temos certa dificuldade de nos encontrarmos enquanto pessoas nas estatísticas e nos mapas, temos uma grande facilidade de nos colocarmos no corpo de algum dos personagens dos audiovisuais, e sentirmos que eles falam mais da vida e do mundo real do que aulas que se pautam por utilizar a fórmula da generalização — e aqui, em apoio a Oliveira Júnior, é proveitoso lembrar que recordar, em sua origem grega, significa passar de novo pelo coração.

Talvez por isso, porque não passa de novo pelo coração, seja que as narrativas sobre o espaço geográfico costumam apresentar-se desprovidas de força para se fixarem na memória. Oliveira Júnior refere-se a essa ausência de força dizendo-se sabedor de que, em muitos momentos, a exceção é construída, mesmo que construída em fragmentos.

É possível que exceções sejam construídas a partir da desconstrução do professor que jamais demonstra duvidar do próprio discurso - qualquer que seja este discurso. Na esteira dessa possibilidade, Oliveira Júnior indaga sobre os motivos que levam muitos professores a manterem relações tensas com os audiovisuais, principalmente os ficcionais, como se estes, ao invés de virem em nosso auxílio, apenas demonstrassem a derrota das narrativas tradicionais.

A indagação de Oliveira Júnior, quer a relacionemos aos audiovisuais, quer relacionemos a outras formas de veiculação de mensagens, remete a outros esforços interrogativos sobre as possibilidades de professores tornarem-se não apenas os autores de narrativas acerca do mundo, mas incentivadores e mediadores da potencialidade de outros tornarem-se também autores.

A pergunta de Oliveira Júnior, aplicada ao conjunto das formas narrativas, converte-se numa inflexão que retorna sobre os autores antes referidos. Na razão em que é pertinente propor que se examine se os caminhos apresentados por esses autores constituem-se em respostas para a interrogação ampliada para o conjunto das relações da geografia e da educação com as formas narrativas.

RUMO? MURO?

Tal como uma moldura que, jogada sobre um extenso conjunto formado pelas sinuosidades misturadas de muitos novelos desenrolados, delimitaria um quadro feito à semelhança da extensão maior e emaranhada, situada ao fundo, assim este texto pretende constituir-se, ele próprio, num quadro (recorte produzido pela intenção de ressaltar uma perspectiva) de sinuosidades misturadas e mais amplas. Trecho de rizoma, rizomático pretende ser.

A metáfora-guia é relembrada pelas linhas que se curvam para voltar a tocar em pontos já percorridos, para, neles, reencontrar de outro modo o antes referido, para, nesse movimento, enxergar a ligação de um significado com outro significado, e a ligação de ambos a um terceiro e outros e, adiante, estabelecer possibilidades multiplicadas nesse circuito.

São muitos os autores e muitos os aportes teóricos aos quais eles remetem. Miscelânea, ecletismo gerador de formas difusas a tentativa de enxergar tantas conexões? Esse circuito é apenas um emaranhado

Revista da ANPEGE. v. 5, 2009 
informe, enredado mas não costurado, uma massa mole incapaz de sustentar-se em pé, não tecido, não coeso?

Ou tecem um tecido que se prepara forte e flexível, essas sinuosidades misturadas?

É possível discernir pontes, canais, fluxos transmitindo sinais de idas e vindas entre núcleos diversos, formando rede?

Seguindo a sugestão aberta pela metáfora da sintaxe, a tentativa aqui é a de apontar para a possível existência de algumas convergências, entre autores/pesquisadores/atuadores diversos, nas quais talvez não seja descabido propor que se examine se nelas não se enfatizam, ou pelo menos se manifestam latentes, as necessidades de:

- Ligar a abordagem do tema polêmico e no momento comentado pela mídia não apenas para solicitar, sobre o tema, o primeiro discurso de cada um, mas a reelaboração dos discursos; reelaboração mediada por: (1) pela escuta do discurso dos outros, e pela comparação entre discursos, pelo exercício de argumentar e contra-argumentar, pelo exercício de gerar perguntas; (2) pela pesquisa sobre a história geradora do fato em discussão, pela pesquisa orientada em busca de respostas para as perguntas geradas pela discussão; (3) pela atenção dada à dúvida sobre a credibilidade das fontes que informam à pesquisa; (4) pelo trabalho de campo e/ou documental sobre fato similar ao fato inicialmente discutido, e pela atenção dada à dúvida sobre o observado; (5) pela elaboração de narrativas sobre o observado, narrativas analíticas sobre o acontecido, e narrativas propositivas sobre o que deva passar a acontecer; (6) pelos diálogos sobre as narrativas; (7) pela criação de meios, ou pelo reconhecimento de meios que já estão dados, para divulgar as narrativas; (8) pela criação de outras vias, ou pelo reconhecimento de outras vias, e não necessariamente realizando toda a sequência a cada vez e nem sempre numa mesma ordem sequencial.

- Ligar o exercício do diálogo ao exercício da deliberação sobre ações possíveis, relativas, em alguma medida, por pequena que seja, a mudanças na produção do espaço geográfico; ligar o exercício de deliberar sobre ações possíveis à prática de tais ações, por pequena que seja.

- Ligar a prática da ação à noção de que a representação sobre o lugar/meu lugar no mundo já é um modo de ação.

- Ligar a prática de ações ao exercício dialógico de significação/avaliação de tais ações, ligar o exercício dialógico ao reconhecimento dos alcances e limites (identificação das causas que impedem os efeitos intencionados de serem produzidos) das ações

- Ligar o exame dos alcances e limites à compreensão dos sistemas onde se contextualizam as ações; identificar escalas e compreender interrelações entre escalas

- Ligar o entendimento sobre o mundo ao entendimento sobre os sujeitos do mundo.

- Ligar o exercício de dialogar/pesquisar/deliberar/agir ao exercício de apropriar-se de linguagens e elaborar narrativas, recriar linguagens.

- Ligar o exercício de apropriar-se de linguagens e recriar linguagens ao exercício de criar meios, ou reconhecer meios que já estão dados, para comunicar as criações dentro do grupo e externamente ao grupo.

- Ligar a comunicação de cada um ao recebimento atento da comunicação de outros.

- Ligar o encontro entre as comunicações à abordagem de problemas e à escolha de problemas, quer sejam ou não estes problemas aqueles que estiverem sob o enfoque momentâneo da mídia.

- Ligar o processo educacional à noção de que as criações, nele produzidas, podem ser remetidas, por diversos meios e em diferentes escalas, como propostas de diálogos com outros e, nesse sentido, contribuem para a construção do espaço público e convertem-se em práticas cidadãs. 
- Ligar esse movimento à noção de emancipação do ser individual/coletivo em relação à aparência das circunstâncias; ligar esse movimento à percepção/elaboração de vivências que manifestem a possibilidade da autodeterminação do ser.

- Ligar ligações através de outras ordens que não sejam necessariamente a ordem sugerida por esta exposição sequencial, e ligar através da criação e do reconhecimento de outras vias, que, diversas nos caminhos, tenham também por princípio a ultrapassagem das repetições que achatam o ser.

Ao contrário daquela frase inicial, utilizada para sugerir a metáfora sintática, a alteração de sentido, nesse conjunto de ligações, é produzida menos pela ordem dos fatores e muito mais pela sua multiplicação.

$\mathrm{O}$ fazer a coisa certa, nesse multiplicar de ligações, está relacionado à centralidade da noção de que, tal como na sintaxe linguística, a compreensão de cada termo só pode ser estabelecida pela compreensão das relações do termo com o contexto. Nessa metáfora, o fazer a coisa certa, isto é, o fazer o processo educacional necessário, está relacionado ao próprio ato de produzir, ampliar e consolidar ligações.

Torna-se explícito, nesse multiplicar de ligações que colocam em pauta a discussão acerca do que seja o certo, aquilo que está sempre presente em todas as práticas mas que poucas vezes é declarado: o princípio de qualquer prática é inseparável de uma escolha axiológica. A questão sobre o sentido daquilo que se faz está, afinal, na raiz de toda prática.

Se o exame de textos e práticas de muitos autores/pesquisadores/atuadores demonstrarem que não é descabido propor que convergências relacionadas a um multiplicar de ligações de fato existem, então é possível propor, pela mesma via, que estamos diante de indícios de uma reconstrução ontológica que remete à concepção de sociabilidade formulada por Moreira (2007), onde o espaço passa a ser concebido como o modo espacial da existência - espaço, condição para o movimento autopoiético humano; espaço, produto do movimento autopoiético humano.

A sondagem da reconstrução ontológica como possibilidade ressalta o que contra a sua realização se faz antagônico.

O desenvolvimento da possibilidade é obstaculizado onde predominar a matriz bancária na formação de professores (no sentido da crítica freireana), quer essa matriz seja veiculada através de práticas tradicionais, nucleadas pelo discurso professoral, quer seja mediatizada por novas tecnologias, se estas significarem apenas o massivo predomínio de pacotes informativos transmitidos aos alunos, ainda que transmitidos de maneira dita competente, quanto à clareza do emitido e aos resultados da recepção. A própria dita competência pode constituir-se em obstáculo, ao obliterar as indagações sobre o sentido com a exaltação do comunicacional reduzido a um repertório de eficiências técnicas quanto à transmissão. Os pacotes informativos, afinal, ligam-se ao quê?

O desenvolvimento de uma reconstrução ontológica necessita, por certo, da exposição informativa, mas sua relação com esta será a relação entre a elaboração crítica do sentido e o uso do instrumento, e não a relação de submissão ao instrumento, como se este fosse, por si mesmo, a sua própria razão e a única razão possível, uma razão apresentada como a-histórica.

Requisitos para fragilizar ainda mais as já precárias condições de trabalho do professor são fornecidos pela modernização conservadora da tradicional educação bancária. Acentua-se a exploração pela combinação de salários achatados e jornadas expandidas para além da sanidade, tanto pelo número de horas passadas em salas de aula quanto pelo número de alunos em cada sala, assim como pelo trabalho que é necessário levar para a casa e para as manhãs e tardes de domingos. Acentuam-se do mesmo modo as exigências descarregadas sobre o professor — ser um repassador competente de informações; ser um recreacionista; ser um comunicador de auditório; ser um disciplinador ao qual se delega a tarefa de 
preencher lacunas deixadas pelos pais, por diversas razões econômicas e culturais, ausentes; ser um ser cordato para com os ditames da direção escolar e de alunos e pais, considerados, pela direção escolar, como clientes; e apenas por último, e muito secundariamente, ou até mesmo de modo dispensável, ser um conhecedor/pesquisador dos conteúdos de sua área e um educador para além do mero repasse de informações. Em suma, ser um ser achatado.

O instrumental representado por novos meios tecnológicos, ao ser apropriado pelo capital como modernização conservadora da tradicional educação bancária, possibilita o aumento do número de alunos para cada professor, através da maximização dos recursos expositivos e, por extensão, coloca o educador em posição ainda mais desvantajosa no mercado de ofertas e procuras dominado pela hegemonia do capital aplicado em posses tecnológicas. Isso ocorrerá tanto na rede privada de ensino, onde a busca pelo lucro máximo, obtido na relação entre aumento da clientela e redução dos custos salariais, escancara-se no cotidiano escolar, como na rede pública, onde a busca pela apropriação dos recursos pode engendrar políticas que reduzem os orçamentos destinados ao uso público para transferi-los, por diversos meios, para o benefício do privado.

Existe, em cada escola, um drama cotidiano que se desdobra em várias faces, e que demonstra o quanto o patrimônio cultural e tecnológico acumulado pela humanidade possibilita, ao mesmo tempo, o desenvolvimento de práticas opressivas e de práticas emancipadoras da experiência humana.

O somatório de muitos bloqueios configura uma inevitável aparência quimérica para os esforços exaustivos e cotidianos daqueles que, contra todas as adversidades, tentam afirmar, através de práticas, pontualizações que indiquem a possibilidade de outro ser.

Na via contraditória, tais esforços demonstram tanto resistências quanto o caráter possível de ser significado, de fato, como quixotesco - o quixotesco que acompanha os sonhos, constituindo-se através de exercícios que evidenciam, ao mesmo tempo, fragmentos de possibilidades autopoiéticas e os limites curtos estabelecidos pelo estrutural.

\section{REFERÊNCIAS BIBLIOGRÁFICAS}

AIGNER, Carlos H.O. Geografia e educação ambiental: construindo a cidadania a partir da valorização do lugar na Escola Municipal Professor Larry José Ribeiro Alves. In: REGO, Nelson; MOOL, Jaqueline; AIGNER, Carlos (orgs.). Saberes e práticas na construção de sujeitos e espaços sociais. Porto Alegre: Editora da Universidade Federal do Rio Grande do Sul, 2006.

CAVALCANTI, Lana S. Ensino de geografia e diversidade: construção de conhecimentos geográficos escolares e atribuição de significados pelos diversos sujeitos do processo de ensino. In: CASTELLAR, Sonia (org.). Educação geográfica: teorias e práticas docentes. São Paulo: Contexto, 2005.

FRANGE, Lucimar B.P.; VASCONCELLOS, Luiz G.F. Oficina de desenho urbano: desenhando e construindo a cidade no cerrado. Uberlândia: Editora da Universidade Federal de Uberlândia, 2004. CD-ROM

FREITAS, José R.V. Os desafios da aula de campo para uma ação motivadora da realidade que cerca o educando. In: REGO, Nelson; PIRES, Cláudia; LINDAU, Heloísa; SUERTEGARAY, Dirce (orgs.). Geografia e educação, diversas vivências. Porto Alegre: Editora da Universidade Federal do Rio Grande do Sul, 2010 (no prelo).

GALVÃO, Wilson. Que geografia se ensina? Um estudo sobre representações de geografia segundo alunos da 6 $^{\text {a }}$ série do ensino fundamental. Dissertação mestrado. Curitiba: Universidade Federal do Paraná, 2004.

GOULART, Ligia. B. Teias que (re)produzem espaços: uma proposta para ampliar a inserção de alunos trabalhadores na sociedade. In: REGO, Nelson; CASTROGIOVANNI, Antônio Carlos; KAERCHER, Nestor (orgs.). Geografia, práticas pedagógicas para o ensino médio. Porto Alegre: Artes Médicas, 2007.

Revista da ANPEGE v. 5, 2009 
GUERRERO, Ana Lúcia A. Contribuições da teoria da atividade para a formação continuada de professores de geografia. In: CASTELLAR, Sonia (org.). Educação geográfica: teorias e práticas docentes. São Paulo: Contexto, 2005.

KAERCHER, Nestor A. A geografia escolar na prática docente: a utopia e os obstáculos epistemológicos da geografia crítica. Tese doutorado. São Paulo: Universidade de São Paulo, 2004.

KOZEL, Salete. Mapas mentais — uma forma de linguagem: perspectivas metodológicas. In: KOZEL, Salete; SILVA, Josué C; GIL FILHO, Sylvio F. Da percepção e cognição à representação: reconstruções teóricas da geografia cultural e humanística. São Paulo: Terceira Margem/Editora da Universidade Federal do Paraná, 2006.

MOREIRA, Ruy. Pensar e ser em geografia. São Paulo: Contexto, 2007.

OLIVEIRA JÚNIOR, Wenceslao M. Perguntas à televisão e às aulas de geografia: crítica e credibilidade nas narrativas da realidade atual. In: PONTUSCHKA, Nídia N.; OLIVEIRA, Ariovaldo V. (orgs.). Geografia em perspectiva. São Paulo: Contexto, 2002.

PIRES, Cláudia L.Z. LINDAU, Heloísa G.L.; RODRIGUES, Milton M. Geografizando lugares: transitando por diferentes ambiências. In: REGO, Nelson; AIGNER, Carlos; PIRES, Cláudia; LINDAU, Heloísa. Um pouco do mundo cabe nas mãos, geografizando em educação o local e o global. Porto Alegre: Editora da Universidade Federal do Rio Grande do Sul, 2003.

REGO, Nelson; SUERTEGARAY, Dirce; HEIDRICH, Álvaro. Geração de ambiências: três conceitos articuladores. In: REGO, Nelson; MOLL, Jaqueline; AIGNER, Carlos (orgs). Saberes e práticas na construção de sujeitos e espaços sociais. Porto Alegre: Editora da Universidade Federal do Rio Grande do Sul, 2006.

REGO, Nelson; SUERTEGARAY, Dirce; HEIDRICH, Álvaro. O ensino de geografia como uma hermenêutica instauradora. Revista Terra Livre, n. 16, São Paulo, Associação dos Geógrafos Brasileiros, 2001.

SANTOS, Milton. A natureza do espaço: técnica e tempo, razão e emoção. São Paulo: Hucitec, 1999.

SCHÄEFFER, Neiva; KAERCHER, Nestor A. Leituras, escritas e falas para que a docência em geografia faça diferença para nossos alunos. In: SCHÄEFFER, Neiva et al. (orgs.). Ler e escrever, compromisso no ensino médio. Porto Alegre: Editora da Universidade Federal do Rio Grande do Sul, 2008.

STRAFORINI, Rafael. Ensinar geografia: o desafio da totalidade-mundo nas séries iniciais. São Paulo: Annablume, 2004.

Recebido em abril de 2009

Aceito em agosto de 2009 